\title{
SILK (AS AN IMPORTED HERITAGE) AND ITS MARKET EVOLUTION IN THE SOUTH OF ITALY CALABRIA EXAMPLE
}

\author{
Dr. Milica KOCOVIC
}

University of Belgrade, Faculty of Philology mickocovic@gmail.com

Prof. Dr. Ljiljana MARKOVIC

University of Belgrade, Faculty of Philology

liiljana.markovic@gmail.com

\section{Luca De SANTO}

hankch74@hotmail.com

\begin{abstract}
In our paper, we are investigating the evolution of silk production and markets in South of Italy, understanding silk as a multi-layered heritage that came to Europe from Asia. Our research is based on historical data, (our and other relevant previous research, archive data etc.) that let us point out on the main historical events that influenced on the silk production phases. Silk is seen as multilayered imported (from Asia to Europe) property, that relates to the meanings of cultural, economic, historical and industrial heritage. In respect to relevant data, we brought main findings of silk production importance (from the past, to the present, with regard to future directions of development).

Research questions:

1) How did silk appear in Italy, and what were the most important influences on the silk production?

2) What importance sericulture had for people involved in this process / main social benefits?

3) What was the relationship between exogenous and endogenous knowledge in silk production in our case?

4) As a dissonant heritage with what kind of narratives silk could be operated today in order to speak its story?

5) What type of governance model is suitable for silk revitalization?

In order to answer these questions, it was important to examine relevant „stakeholders"(institutions, involved sectors, sericulture, markets and evolution of mentioned) (with a specific focus on Calabria region) helped us in bringing conclusions about total processes around silk production in South of Italy.
\end{abstract}

Key words: Silk production, multi-layered heritage, silk markets, South Italy, Calabria 


\section{INTRODUCTION}

In this paper research questions goes with the frame line leitmotif(s) of our previous research findings and the fact that silk is very important because it summarize and synergize the meanings and values of: cultural, historical, economical and industrial heritage. We decided to start this part with elaboration of our previous research findings, because they all have elements of universality according to our two case studies (Serbia and Calabria). This elaboration is important because our research questions are shaped in line with our previous findings, in order to test hypothesis and their universalities, through new case study. Of course, our plan is to cover all the important European countries that were involved in Silk production, in our future research, but with same frame, that would enable distinguishing similarities and differences for each. Namely, in this paper we start from our four main previous findings for silk and silk production.

1. (Silk and silk production) were combination of exogenous and endogenous knowledge (see also Djukic 2017);

2. (Silk and silk production) are dissonant heritage (see also Sesic, Rogac 2014);

3. (Silk and silk production) had a strong social component for the involved people in process (in case of Serbia and Calabria case);

4. (Silk and silk production) represented the clean industry that makes decent argument for silk / sericulture re-start in the name of sustainable development (Kocovic, Aleksic, Markovic, 2017).

The pure essence of the silk meanings can be seen through the four main findings about the fact that as an imported phenomenon (from Asia to Europe), silk still (constantly) holds added knowledge that was (re)shaped many times during its travelling along the silk roads. In this context a sense of cultural dimension was established, besides the economic. To be clearer silk as a product of sericulture is a combination of exogenous and endogenous knowledge, as a practice(s) and a work activity. Previous can be understood through the fact that the silk production as an (economic and cultural) activity combines traditional and imported knowledge in the processes and management practices (...) Moreover, the organization of sericulture work assumed linking of agriculture and textile industry, or from labor perspective farmers and workers, where mentioned represented link in total chain of values in the process of silk production (Kocovic, Aleksic, Markovic 2017). In some (silk) production cases labor was elastic working in agriculture or industrial departments, but in constant touch. On the other hand, in Japan proto-industrial phase of silk development it is notable that they demarcated agricultural and proto-industrial regions through combination by employment in the terms of labor structure that combined both aspects (Hauser, 1974). Previous also mean that the silk and silk production allowed creation of (social, financial and cultural) linkages between urban and rural 
territories or, it was the bridgehead for people from the rural and urban areas. The use value of the silk had many variations, from textile fetishistic phenomena, to the values that came with artisan or native labor work with add through the silk drawing etc. Silk use and availability evolved from a prestigious luxury good reserved for the elite, to the gradually accessible good for all the people. Specifically interesting for this research, is the fact that silk had the meaning of real substitute for the money as a means of payment and the credit guarantee. Previous is related to the value and importance that silk had in the middle age in the South of Italy. Silk had very sophisticated value as a real economic resource. Another important aspect of the silk is that it essentially carries meaning and "significance" of dissonant heritage. This means that interpretations of dissonant heritage are tightly influenced by cultural memories and identities of interpreters. The experiences of the present are largely based on specific knowledge of the past - thus the ways of experiencing the present are influenced by different perceptions of the past with which it can be connected(...) all the heritage is a contemporary interpretation shaped by narratives of history(...) (Kocovic, Aleksic, Markovic 2017, Sesic, Rogac 2014). Dissonant heritage often opens up ambivalent topics and largely unwanted past through the narratives which is the right key for future management solutions for silk heritage re-activation (Kocovic, Aleksic, Markovic, 2017, Sesic, Rogac 2014). This is important (and dangerously indicative) to the extent that it could obscurely overshadow every other finding related to the silk. People from countries with a long tradition in the silk production (the case of Calabria and Serbia) seem to have lost their collective memory about it. The result of a collective erratic memory in the sense of sericulture is nowadays reality. Although the generations of grandmothers were directly involved in the silk processes (still) until the Second World War, their grandchildren do not even know that silk was produced in the same territory where they live, and sometimes in the roofs of their houses ${ }^{1}$. Losing collective memory is dangerous because it implies a loss of culture and identity. Sometimes it even happened strategically through the system politics and policies (implicitly or explicitly), with the aim of creating a unique (national) culture. This practically led to the assimilation and the disappearance of differences. Therefore, the significance of existence of the various interpretations around such heritage (local, national, international context) is obvious. Moreover, in narative of global phenomena such as silk, each interpretation is equally important in order to understand the phenomenon, (and create future strategies of development). Strong social component in our both research, previous example of Serbia / The kingdom of Yugoslavia shown that sericulture as an activity could be understood as a social entrepreneurship in today's language that allowed additional money for involved people. In case of Calabria it meant surplus or first capital accumulation. In both

\footnotetext{
${ }^{1}$ In Calabria, South Italy region, cocoons production in early phases all until $16^{\text {th }}$ and $17^{\text {th }}$ century took place in the roofs of houses. Our field research pointed based on direct interviews that until Second World War, people produced bombix mory until cocoon phase using roofs of their houses.
} 
cases - vulnerable people from agricultural area that were poorest population, benefited directly from silk production. Additional examples reinforce the social aspect that the silk production carried on a planetary level. For example, in Spanish colonial America (proto-industrial phase) surplus of native women in peasant households operating on looms was channeled into regional trade by the royal and merchants partnerships. In same proto-industrial period Japan had peasant producers, and this was specific example, because small rural producers would cover all the process activities from beginning to the final product - silk textile, selling it to the merchants. This allowed strong rural development and proto-industrial profits for the rural population. Even with a modernization and adoption new technologies, Japan kept social aspect strong through high labor specialization, that allowed social mobility which helped landless people who worked within enterprises to get their surplus (Hauser, 1974). The foruth and very universal previous research finding is supported by the fact that everything around silk is clean and sustainable, this means that we talk about clean industry. This finding makes silk and sericulture very desirable in the context of possible re-innovation; re-start, through alternative touristic narratives, new forms of creative and cultural economy that could be supported by real multilayered heritage meanings and importance of silk - as it is.

In this research we used historical approaches, archive and previous research data, field research that allowed us to come to / and strengthen previous universal findings. We also relied on previous relevant research in especially with an attempt to better understand historically aspects and implications of world's silk markets in general, that allowed us to bring more specific conclusions about Calabria (history of) silk market evolution. In this paper we did comparative analysis of our chosen case study of Calabria, with our previous (paper) case study of Serbia (adding sometimes similarities with other world's cases) which exactly allowed us to encircle our important universal findings related to silk.

\section{SILK ROADS AS THE INTERCONTINENTAL MOVEMENT CORRIDORS}

Along the silk roads not only silk, but numerous of goods were exchanged differently. This assumed long-term (speaking on millenniums level) continual commitment of processes that implied permanent connectivity of cultures, languages, people, and goods. Primarily trade, and secondary (happening all in parallel) previously mentioned exchanges contributed to the contemporary multiperspective meanings of the silk roads. We can say that silk roads from the beginning, have been representing the first transnational and global corridors (without knowledge of these words, and much longer before these words appearance) that provided migrations of vibrant values through the respect of culture and economy. The trade within silk roads took international proportions as initial reason point, evolving into different types of products exchanges. Processes within the silk roads have been constantly reshaped, allowing deeper understanding and acceptance between (different) people. 
This created firm relations between people, culture, environment, within natural landscapes and associated capillary tracks, trails, routes, paths of latter called - silk roads. Besides the silk, parallel exchanges that took place on these roads (such as: languages, religions, literature, writings, scripts, spices, legends, materials, grains, animals, people etc.) enabled the great cultural mix and exchange. In this sense silk roads are a planetary phenomenon due to the strong cultural domino effect. (Kocovic, Aleksic, Markovic, 2017).

\subsection{Intercontinental silk migration in terms of production through the phases}

Having in mind relevant previous research, we can make few important conclusions about directions of silk arrival to the Western world and specifically Europe.

The $1^{\text {st }}$ line of silk and sericulture expansion from Persia towards the Europe happened through (Justinian) Byzantine emperor channels (nowadays parts of Balkan) - East Rome Imperia around $6^{\text {th }}$ century AD. This also allowed silk to appear in all Byzantium territories - Mediterranean costal parts (from South of Greece and Italy (Calabria) to the central parts). This is very important for our research, because it indicates that silk arrival in terms of production actually happened at the same tame in Calabria and Serbia. The only difference lies in the fact that Calabria sources led to the first phases of production that dates from 11th century, and Serbian traces of organized production dates from $18^{\text {th }}$ century. On the other hand, many sources indicate that the white mulberry, in addition to the black exists within the Balkan territory from the $6^{\text {th }}$ century, which exactly coincides with the $1^{\text {st }}$ line of the silk production arrival.

The $2^{\text {nd }}$ line of expansion came with Ottomans, who brought intercultural boost for both Europe and Asia, after $8^{\text {th }}$ century (From Sicily to Spain).

The $3^{\text {rd }}$ line of sericulture spreading happened between $15-16^{\text {th }}$ century in Europe, and this was the very beginning of creation history of silk (proto-) industry in Europe (and World textile industry).

The $4^{\text {th }}$ line could be seen as industrial level of sericulture, with similarities and differences based on authentic approaches and system measures that each country took in order to regulate silk market. This phase was pushed by the development of crafts and manufacture in Germany, United Kingdom and later (from $18^{\text {th }}$ century) United States. Also in $17^{\text {th }}$ and $18^{\text {th }}$ centuries was the momentum of proto-industry that was followed by turbulent changes at planetary level in textile industry, with the aim of conquering the largest possible foreign markets.

The $5^{\text {th }}$ line, International turbulences the end of $18^{\text {th }}$ and $19^{\text {th }}$ century focus on the trade, economic growth, creation of the new national countries and cultures, unifications, serious regulation approaches etc. The detection of the pebrine disease happened in this line. The pebrine is disease of silkworm, caused by protozoan parasite named Nosema Bombycis, appeared around 1840 in France 
and wide spread initially in Spain and Italy, and then - gradually in the rest of Europe, Turkey, Middle East, Persia, India, China and Japan (Federico, 1994). The damages done by the pebrine were serious in every country and brought to the collapse of European sericulture (France switched from an annual production of 20.000 tons of cocoons in 1853 to 4.000 tons in 1865 (Marcelli, 2013) ${ }^{2}$. The market share of Asian silk increased to about $40 \%$ after breakout of pebrine in Europe (Federico, 1994) ${ }^{3}$.

The $6^{\text {th }}$ line is silk disappearance as a process of the silk suppression by the artificial silk, globalized and accelerated after WWII and mass use of gasoline and it's (by) products.

These phases are given as a reflection of changes in terms of silk availability, (both for countries and for people (classes)). Different phases also indicate the need for evolution of production methods that initiated its ever-increasing use until the appearance of artificial silk that was cheaper (even difficult to say substitute) than natural silk.

\subsection{Global trajectories that influenced the Worlds silk markets}

In time from $15^{\text {th }}$ to the beginning of $19^{\text {th }}$ century (first three lines of silk movement) total output and trade of materials (raw or final products) exponentially increased on the level of world economy. As author Fennell Mazzaoui added in line to previous mentioned textile development it happened, despite short-term downturns (related to political, economic and demographic trends in various regions of world economy (Fennell Mazzaoui 1997). Until the early modernization / protomodernization $\left(15^{\text {th }}\right.$ century, from $1^{\text {st }}$ to $3^{\text {rd }}$ line of silk movement) processes and activities related to the textile production have supported largest workers group outside the agricultural sector (that was the most important in that historical time). Mercantile capital age in feudal system, allowed the integration of regional fragmented economies into the wider international network of commodity (Fennell Mazzaoui 1997), so this early exchanges had the potential to effect multiple transformation especially important in terms of market evolution through production relations between interest sides (merchants, aristocracy, producers, consumers). Time from $15^{\text {th }}$ to $18^{\text {th }}$ century is characterized by small-scale production which is considered to be the beginning of the organized textile (and as well silk) production, these were in most cases very fragmented economies. As author Huston notes traditional local handcrafts had always existed in rural areas, but in the period from the fifteenth to the nineteenth century a new economic development occurred in many regions to which considerable attention is now being paid (Houston, K.D.M. Snell 1984). This period is also characterized by an expansion of rural industry without major changes in the techniques or scale of production, and as a development phase it is termed as proto-industrial, as a industrialization before industrialization

\footnotetext{
${ }^{2}$ The damages done by the pebrine were serious in every country and brought to the collapse of european sericulture (France switched from an annual production of 20.000 tons of cocoons in 1853 to 4.000 tons in 1865 ${ }^{3}$ until the breakout of the pebrine disease European silk industries used very little of Asian silk, but the pebrine crisis changed it all
} 
(Houston 1984, Kriedtc, Mcdick 1977). Proto-industrialization scholars aimed to explain the transition from feudalism to capitalism, as well as the social transition - traditional society of peasant agriculture to the modern industrial world. Furthermore, Huston et all noted that drawing on the classical economic theory that markets overseas incorporated productive resources more effectively than did local markets, it is argued that 'foreign trade was not only the " handmaiden " of protoindustrialization, but, indeed, its " engine of growth" (Huston 1984, KMS 1974). Because the trade is considered as proto-industrial engine of growth, we decided to elaborate further some ideas of previous research that will help understand better internal and external dynamics that influenced on textile and silk markets.

In terms of European textile markets and international activity main actors, we can separately distinguish were English, Dutch, Spanish, French and Portugal in their attempts to spread markets from internal to European, but furthermore (mostly through colonial world) in all the other parts of the world. Although Italy was the largest silk producer in Europe, producing half of the total European produced silk during this period, their export direction was primarily for the European market, and then for other worlds markets in terms of sophisticated silk products intended for elite consumption ${ }^{4}$. In 1580 The Kingdom of Napoli and Naples government regulated the sericulture sector by an agreement known as Concordia, providing that all the raw silk (threads) produced in The Kingdom had to be delivered to the capital city where it should be worked in order to export both threads and textiles (Ragosta, 2009). Even as main producer, Italy imported raw silk from Levant, and other Asian parts. In $16^{\text {th }}$ century Spain had attempt to integrate sericulture markets with colonial South American, since they introduced sericulture to the natives (but also wisely expropriated their traditional knowledge about textile in order to be able to satisfy specific market taste and demand) (Grijalva 1989, Mazzaoui 1997). Previous mentioned Spanish attempt was disabled by extensive Chinese exports through the triangular trade route China-Manila-Spanish America with involved Chinese community on Philippines that later in $17^{\text {th }}$ century represented dominant China silk export direction ( Chao 1989, Mazzaoui 1997). In proto-industrial phase exchanges were based on different types of products with other countries ${ }^{5}$ and extensive export that brought significant capital (gold, silver, diamonds, luxury goods and money). Generally, Mediterranean and Balkan countries except cotton and wool, developed silk production (but also other specific types nature textile that came from Mediterranean plants such as ginestra textile) because of suitable climate. When talking about territory, European silk was produced along the Mediterranean coastal zone, and Balkan, while Asian

\footnotetext{
${ }^{4}$ We do not include them in above mentioned colonial European countries (because they were not) which was especially important in terms of spreading markets during proto-industrial time.

${ }^{5}$ for example they exchanged luxury goods for Bengali and Indian cotton, and India exchanged silk for African slaves, gold and ivory.
} 
production was spread everywhere - from the $\mathrm{China}^{6}{ }^{6} \mathrm{Japan}^{7}$, to the Middle East ${ }^{8}$, Central Asia ${ }^{9}$, and India, later in $19^{\text {th }}$ century new areas appeared (Wuxi in Central China or Kashmir in India) (Cafagna, Federico 1992, Federico 2009). English, Dutch and other northern countries put maximum effort on wool and cotton internal production, while raw silk was imported (the reason was the same - climate). Asia and Europe had very strong interrelation in proto-industrial phase in terms of trade (of silk / textile etc). Europe was the main importer of Asian goods, later exporting them towards other continents ${ }^{10}$. In terms of transportation options, textile industry strongly relied on road traffic (silk roads, Saharan caravan and others) and later oversea transportation towards colonial but as well noncolonial countries (North, South America, Africa, India and other Asian seaside parts). Europe could not ever come nearly close to the level of Asian production of silk, primarily because of the cultural differences. Namely, Asian countries and people have always been strongly attached to the tradition, identity, meanings, rituals, societal values that were transported as well to the fashion and taste for textile (which shaped total Asian demand). For this reason Asian people always preferred their own textile, which implied small proportion of European cloth in Asian markets (Mazzaoui 1997). Moreover, Asian markets have been developed based on internal markets on the first place, and after on export, while European countries in opposite have always been searching for new markets - mostly external. Differences also came from demographical, spatial, territorial facts. When talking about European and Asian trade Mazzaoui notes that European trade with Asia was indicative of the weak demand for western goods in Asiatic markets. Asian cloth producers enjoyed a competitive advantage over European exporters by virtue of their access to sophisticated technologies, a highly skilled, lowwage labor force and well-established distribution networks (Mazzaoui 1997). It is not only technology and economic organization, but also socio-cultural norms that helped in processes of governing the usages of textiles, as market social, political or ethnic status or as ceremonial objects that also favored the consumption of traditional silk and cotton products of the region (Mazzaoui 1997). Mentioned aspects made Asian trade solid and strong over time, because internal demand was satisfied by internal supply, but also added values were created through the export. Interdependence of proto-industrial markets was strong, so purchasing power at one market would have implication for lower prices in another (Herzig 1990, Mazzaoui 1997) ${ }^{11}$. In proto-industrial phase of development

\footnotetext{
${ }^{6}$ Central provinces around Shanghai, and Southern around Canton;

${ }^{7}$ Central island;

${ }^{8}$ Turkey, Lebanon, Caucasus countries;

${ }^{9}$ Iran, Turkmenistan;

${ }^{10}$ European countries mostly imported raw or different cheaper materials, where they would put some more added values, and later export to the other countries and colonial worlds.

11 "The regular export of Iranian raw silk to Europe began as early as the twelfth century with the establishment of a significant silk industry in central Italy (Lucca, later Florence and Venice all depended on the Levant for a part of their raw silk supples. Until the $18^{\text {th }}$ century most of silk exported from the Levant came from Iran.'(Herzig, 1997)
} 
countries would have apply elementary self-regulating measures in terms of guarding internal markets from price dumping. For example, British export towards colonial markets although highly depended on merchants, recorded most important growth (from England, Scotland and Ireland) thanks to protectionist measures and parallel expansion of the production where medium quality goods from low-cost producers gradually edged out higher priced in American markets (Harte, Pointing 1973, Mazzaoui 1997). Ottoman case had many similarities with European proto-industrial production, in this sense Author Genc noted that extension of mercantile control over spinners and weavers was restricted by interests of craftsmen and by the state control of wages and profits through limitations on the accumulation of private capital, this note illustrates instruments, actors and strategies (Mehmet Genc 1996) ${ }^{12}$. Author Cizakca also mentioned that Ottoman Industry was already under the pressure of European competition at the second half of $16^{\text {th }}$ century $^{13}$ (Mazzaoui 1997, Cizakca 1997). Because European countries in this phase had almost constantly increasing demand for the raw materials (mostly because of lack ability to produce internally on a larger scale raw materials, but instead final products), this would implied rise of raw fabrics at the international markets and price fluctuations. Speaking about interdependence of that time, it is valuable to mention that for example Low cost English and Dutch wool, and Indian cotton, actually cut off the Iranian workers output, and on contrary the rise of Iranian silk prices had strong impact of European manufactures (which mostly used Iranian raw silk). Such situation often led to the rise of European (manufacturers) demand for Italian (French and Spanish) raw silk. Until the end of the $16^{\text {th }}$ century Iran was considered as principal supplier of superior grades of raw silk to European, Ottoman and Indian markets. Caspian silk export was carried by Armenian merchants and the southeast Iranian production places exported silk to the India, moreover Iranian silk products were marketed primarily externally on Europe, and they were considered as inferior compared to Italian (in terms of quality, fashion and price) but also uncompetitive fully to the cheaper Indian products. (Mazzaoui et. all 1997, Morris Rossabi 1990). Sometimes Europeans had the roll of Trade Bridge between other sides, such as the case of the Portugal since got Macao acquisition becoming the connector of Chinese and Japanese trade in the $16^{\text {th }}$ century. Portuguese merchants hold Eastern coast of Africa connecting to Oman and India and later Morocco and West Africa and Brazil, while Asian merchants covered Tanzania, Zanzibar and Kenya as Africa markets (see more: Mazzaoui, 1997). Indian textile was superior by many terms (price, low cost labor, skills, flexibility and adaptability towards demand etc), that made them main supplier in the global economy of quality cotton. As such, India was major supplier for Southeast Asia, Dutch and

\footnotetext{
${ }^{12}$ Ottomans Provision policies - ensured adequate supply on international markets , with fiscal measures on exported raw materials and final products, that helped in terms of future introduced in $18^{\text {th }}$ century product Mohair for the luxury markets

${ }^{13}$ European, mainly Italian demand for raw material increased substantially at the second half of $16^{\text {th }}$ century(...) Traditionaly Italian city states. Ottoman raw silk was used mainly as a supplement for French and Italian silk. (Cizakca 1996)
} 
also Japan (until Tokugawa Shogunate, and his strong direction and commitment in the development expanding sericulture and textile industry in Japan). Japan was successfully prepared for the future modernization and real industrialization because of actual combination of few connected development directions. Namely, Japan was relatively isolated from external influences so they brought completely authentic solutions when Tokugawa Shogunate encouraged the expansion of sericulture and cotton cultivation with a help of han provincial governments (Hauser, 1997). What makes Japan approach towards silk development different than any other is the fact that producers of the final silk products were peasants who processed their own raw materials from the first to the final stage, after they would sell these products to the merchants (who in most cases used credits). In the $18^{\text {th }}$ century rural producers in Japan increased steadily their market share (to the detriment of urban artisans), and all until arrival of technology higher specializations did not exist. This created strong rural communities, and great social mobility because of new jobs that will to be created in future industrialization. Also, this allowed land-less people to get their fair shares, what actually represented capacity building in all the terms. Japan proto-industrial phase could be explained as a "strengths reinforcement of the vulnerable, through reduced improvements by factual achieved power". For the African (mostly elite demand) it is important to mention their strong cultural focus, similar as Asian. Namely, in relation to the imported products from abroad (Europe, China, India) exporters had to have in mind African sophisticated taste for textile, that could make added values. Author Adenaike notes thet extile had to include the rich symbolic and religious significance attached to traditional cloth enhanced its value as a ceremonial object, a form of stored wealth and a preferred medium of exchange in barter, gift giving and formal tribute. In clothing, it served as a visible marker of social status and official standing (Maureen Fennell Mazzaoui et. all 1997).

In proto-industrial phase all the social, cultural and economic changes initiated creation of first systematic solutions (politics and policies) that allowed regulations in field of silk and in general textile production. In terms of world's silk markets, it could be noted that their change was initiated by the increased demand (from the $17^{\text {th }}$ century silk entered its democratization phase, when it become available for most of the people, contrary to the previous logic - only and exclusively reserved for the rich - elite people. Silk market evolution happened also as a combination of cultural, societal, technological, logistic and communication channels but national frames and new borders, as well. Authors Federico and Cafagna noted that silk production did not change much after $17^{\text {th }}$ century. Same authors mentioned that main producing areas in $17^{\text {th }}$ century in Italy were located mostly in the northern parts (Piedmont, Lombardy, Veneto), indicating that sericulture was first introduced at South of Italy, and later slowly expanded northwards during the early modern age (Cafagna, Federico, 1992 ). More about possible reasons for this industry migration fact will be elaborated in next part. Silk production in South of Italy: The case of Calabria. 
It's interesting to note that if the traveller nowadays goes through Calabria searching for any silk heritage, he will find only few signs. Comparing mentioned finding about few traces and signs of silk heritage in this area, it is hard to believe that Calabria was one of the main areas of silk production in Europe for very long period (starting at least from 10th century to the second half of 20th century). The progressive abandonment of the mulberry tree cultivation and its replacement with other cultures (such as: olive trees, vineyards and citrus) slowly removed the signs of the „silk wor(l)d“ not only from the rural landscape but also from the mind of the local residents. In the past mulberry trees were planted almost everywhere - both in the coastal and mountain areas. Moreower it seems difficult even to imagine that once upon a time mulberry trees were widely spreaded in the rural landscape. We could conclude that now there is only few visible marks of silk history in this region.

$>$ Nowdays this picture with mulberry trees landscapes is gone - without mass evidence in the landscape,

Few examples of industrial heritage is very low industrial trace - in comparison to the 120 silk spinning mills working in Calabria in 1863 year, only few ${ }^{14}$ of them have been restored in order to preserve their cultural value and historical memory from the oblivion,

$>$ Cultural memories around silk of the local people are disappearing - small nomber of elderly residents still has knowledge about silk production, processing etc.

These conclusions are even grimmer if we add them the fact that silk as economic activity more than all, had a strong impact on Calabrian economy, culture and landscape throughtout the history.

The export of silk (made in Calabria) infact constituted, the only industry in the whole economic history of the region. This branch of industry was able to provide a constant inflow of foreign capital for many centuries. Silk industry, throught the different steps of production process, included all sectors of Calabrian society at the time, ensured a major source of income. Yet, the crisis of the silk production arrose in the late XIX century and the economic policy decisions of newborn The Kingdom of Italy determined the development of more profitable agricultural crops (such as: citrus, olives and other fruits and vegetables). Not single of mentioned crop could ever reach the level of silk success - both as regards the benefits for the regional economy and the number of people involved in various ways in the production process. Today only few material evidences of this important heritage are visible generally in small museum, churches and private collections, but, fortunately in the last years there has been an increasing interest for sericulture and a new

\footnotetext{
${ }^{14}$ We mention here the spinning mills „Gaudio“ (with antiquate but still working technology) in the Mendicino municipality, converted in museum of Silk and the in Cannitello di Villa San Giovanni that are actually neglected because of disagreement between the owners and the Municipality about their use. Other former spinning mills have been renovated and converted in restaurants or just abandoned and lie in ruins.
} 
consciousness of the importance of common memory retrieval as in terms of academic research as in terms of political requests coming from the civil society.

\subsection{Silk production and historical turbulence: Calabria until $16^{\text {th }}$ century}

Many authoritative studies (Federico, 2009; Capalbo, 2004) have carefully described the importance of Italian peninsula in production and trading process of silk products all over Europe ${ }^{15}$, and the historical path starting from the introduction of mulberry trees by the Byzantines, passing by the monopolistic position at European level (in $15^{\text {th }}$ and 16th), until decadence and definitive crisis of 19th and 20th centuries. Author Capalbo notes that in Sicily and Calabria, where sericulture was already practiced under Arab and byzantine domination (9th century) the production of silk textiles had a period of strong development and creativity as a reflection of integration of different cultures, favored after the Norman conquest, by the decline of manufacture centers in Persia and Syria overwhelmed by the invasion of Mongols (Capalbo, 2004). Within the framework of silk manufacturing in Italian regions, Calabria represents, in our opinion, a particular case study full of food for thought and worthy of further desirable academic deepening. First of all we can say that all the leading researchers of Italian sericulture agree that Calabria and Sicily were the first regions ${ }^{16}$ where the Byzantines started a massive cultivation of mulberry tree and silk production and that, for the period between XII and XVI centuries, virtually all the silk on the main European markets (Lucca, Firenze, Venice, Genoa, Milano, Lyon was imported from Southern Italy ${ }^{17}$. Another important issue that should be mentioned here is the large-scale distribution all over the regional territory of mulberry growing, silkworm cultivation and silk production ${ }^{18}$, favored by both ideal climatic and land conditions and a semi-feudal social organization based on spread family work in rural areas. In his

\footnotetext{
${ }^{15}$ In Europe silk products were already popular and appreciated from Roman times. the Romans however didn't know the secret of the origin of this material and were limited to import from Persia and China, throught the Silk Road.

${ }^{16}$ Silk production in Calabria started during byzantine rule when plenty of mulberry trees were planted and the growth of silkworm was implemented; the Franch historician André Guilou mentioned a document dating back to the $11^{\text {th }}$ century, attesting the existence of a mulberry garden with thousands of trees; we have no evidence of the presence of spinning mills in Calabria during the Byzantine rule, while we know that during the second Crusade (1147) the Normans raided the byzantine silk production center of Corinth, capturing tools and weavers and bringing them back to their possessions in Calabria (see Muthesius, 331). In 12th century the Catanzaro area supplied of silk merchants coming from almost all of Europe and the city was famous for its fine fabrication of silks, velvets, damasks and brocades.

${ }^{17}$ At the end of XV century, while the cultivation of mulberry was moving first steps in Northern Italy and in France, silk made in Calabria reached the peak of $50 \%$ of the whole Italian/european production (see Malanima, Federico, Fusco, Battistini). As the cultivation of mulberry was difficult in Northern and Continental Europe, merchants and operators used to purchase in Southern Italy raw materials in order to finish the products and resell them for a better price.

${ }^{18}$ It was really an impressive phenomenon: according to statistics Malanima reported in his study Le sete in Calabria, in 15th century about one hunderd thousand Calabrian people were in various ways involved in the production process; if we consider that at that time total estimated population was about 500.000 people, we can say almost every family was practising sericulture and getting some income from it. this specific form of mass production had a clear socio-economic relevance but, at the same time, its excessive fragmentation will later represent an obstacle to modernization and industrial development.
} 
work Croniche et Antichita' di Calabria, Girolamo Marafioti (Placanica, 1999) wrote that in Calabria everyone could get dressed in silk, because everyone, also poor people produce by themselves, in their own houses, enough silk to weave their clothes.

In the first half of 17th century, especially for fiscal reasons, Calabria silk production and trading were not prospering like in the past, as could be seen from data analysis of average tax revenue on Calabria silk (from 55.362 ducats of 1580 to 39.942 ducats in 1641-42 and to 31.204 only ten years later) that clearly show decline in production (Anania, 2001). Ironically (or not) the longest and most stable period of production can be bounded with the feudalistic and proto-industrial feudalistic phases until the late $18^{\text {th }}$ century, when peasants were living and working at subsistence level with their families within latifondo, huge agricultural estate whose owners were usually descendents of old aristocratic families, in a context of dramatic social immobility.

For landowners silkworm growth and breeding was considered as a seasonal work in wider agriculture context. Work was usually assigned to women that could be done as other added farming activity. Silk activities for involved landless people meant first accumulation, or first share of actually valuable good that can be exchanged for money or other needed goods. When talking about the time of feudalism and proto-industrial era, we must have in the mind that this was the time of the first private expropriations of land by private land owners - aristocracy, who owned huge plots of land. The land in feudalism would have become someone's private property either through the direct family connections with the monarchy, or through the participations of ordinary people in the warfare for the monarchy. The Kingdom of Napoli was under Spanish crown, at that time, it means the collected money through the taxes in the main were used to finance military campaigns to expand or defend the territory of the Spanish monarchy and to conquer new colonies in America.

The landowners - aristocrats had in their personal possession a vast land. Silk processing within their land would be outsourced to a few directions: agricultural, manufactural and trade phase.

$>$ Agricultural phase was delegated to the farmers especially women (planting and cultivation of mulberry trees, harvesting of leaves and silkworm breeding);

$>$ Manufacture phase referred to the relying by craftsmen (maestri trattori) - the phase when the silk strand was obteined by brushing the boiled silkworm cocoons. It was wound on the reel ${ }^{19}$ in order of getting raw silk;

Aristcrtats and merchants were directly involved in taking care of trading, and sending the raw silk mainly on other markets (Napoli and Messina markets ${ }^{20}$ ) leaving a small ammount to be used for local consumption.

\footnotetext{
${ }^{19}$ cocoon drying, boiling and spinning
} 
The incomes coming from the silk industry were clearly unbalanced in favour of the landowners who controlled the entire silk production circle. They were strongly involved in every process, by holding most of production under their direct controle. Silk incomes were extremely important for the farmers too, because they represented the only „exchangeble“21 or liquide source of income to pay back the debts and advances. The production relation between land owner and peasants was determined by contracts. Of course, land owners would have been always better positioned. Peasants have a place to live in exchange for work in agricultural activities. After harvest of crops, land owner would usually get $2 / 3$ of total, while $1 / 3$ would go for peasant and his family. Almost the same logic as previously mentioned was with sericulture: land owners got the most of the production because they were monitoring the whole process. Namely, as owners of the mulberries, they sold leaves to the peasants in order to make the silkworms grow. After peasants made cocoons the landowners would get $2 / 3$ and next step was to pay few days of master spinners work. Finally, through the merchants silk resells of threads would be sold to Naples or Messina markets.

We may shortly conclude without fear of contradiction that sericulture had a deep impact on Calabria society during many centuries because it consolidated the power and favoured the enrichment of a handful of landlords. Silk production also represented one of the main fiscal resources the Spanish monarchy ${ }^{22}$ used to ensure easier access to international credit market, especially during the economic and financial crisis in first decades of XVIII century. For the landless people the rural population who lived in a state of slavery and submission, it provided the only income.

Silk industry, throught the different steps of production process, included all sectors of Calabrian society at the time. We must not forget how the political instability, the endless cycle of foreign dominations and changes of administrations (Byzantine, Lombards, Normans, Arabs, French Angevin, Spanish Aragonese, The Kingdom of Napoles under the Bourbon dinasty, Kingdom of Italy under the Savoy dinasty), all along its turbulent history has slowed down the economic development of the region, favouring socio-cultural stagnation typical of a colonial exploitation whose characters are still visible nowadays.

\footnotetext{
20 this kind of economy (based on raw material production) went on without considerable changes until the beginning of 19th century when many efforts have been made to industrialize the spinning, dyeing and weaving process, in order to obtain a most valuable finished product.

${ }^{21}$ The peasant (responsible of mulberry tree cultivation, raising silkworms and harvesting cocoons) was rewarded with an amount of final product. However peasants were not interested in silk for its use value but for its exchange value, as a liquid property to pay back a debt or to buy something on the local market.

${ }^{22}$ Southern Italy had formally become part of Spanish Empire with the treaty of Lyon (1504).
} 


\subsection{Silk production in Calabria: challenges by phases}

The silk produced between $14^{\text {th }}$ and $16^{\text {th }}$ centuries in Calabria was the most famous and the best selling not only in Italy, but in Europe as well. Namely, since the 50\% of the total turnover of silk in Italy was produced in Calabria by the 16th century, for the same period Italy was considered as the largest silk producer in Europe. It is easy to conclude that the Southern region of the Apennine Peninsula, (at that time splitted in two provinces Calabria Citeriore and Calabria Ulteriore) contributed mostly to the previous mentioned statistics (Malanima, 2004 ). In the 16th century, Calabria was characterized by a strong demographical and economic development, mainly due to the increasing demand of silk products and the simultaneous growth of prices, and became one of the most important Mediterranean markets for silk (Galasso, 1975). During the $17^{\text {th }}$ century silk production in Calabria begin to suffer by the strong competition of new-raising competitors in Italian Peninsula (mainly Piedmont, Lombardy and Veneto) and Europe (France), but also the increasing import from Ottoman Empire and Persia. It was the period just before proto-industrialization that assumed slowly concentration and centralization in terms of production (within the first factory buildings appearances). This phase is characterized by constant innovation in terms of technologies and skills, artisan works, and all the aspects that added values to the final product. Northern cities of Apennine Peninsula (after being for centuries main importers of Calabrian silk) started to produce silk themselves and/or to import silk form Levant. Calabrian silk slowly became uncompetitive.

Why this un-competitiveness has happened? The main causes of the decadence of sericulture in Calabria during the Modern Age should be searched in the political, economic and social context of the time in which it ocurred. The colaps started during the Spanish domination on Southern Italy when Calabrian economy assumed features of typical colonial and self-sustaining vicious circle of feudalistic capitalism. Landless people gave their work in exchange for modest and even poor life and/or peasants worked on the owners land and their efforts were expropriated by the landowners (who usually worked in the cities as lawyers or clerks). The production relation between land owner and peasants was determined by contracts. Of course, land owners would have been always better positioned. More about the essential expression of this unfavorable relationship between producers and owners is about (future coming) cruel capitalistic logic.

The challanges in terms of silk production in Calabria can be explained as:

An excessive and fragmented (production) (in terms of large number of small scale producers almost in every village people were involved in cocoons production); 
Low cost work force, production and export, strict regulation ${ }^{23}$ (aimed to keep the Status quo and ensure internal silk market. Calabria cept its role of raw silk reserve for Neapolitan or Messina workshops and markets;

Feudalistic work organization allowed landowners to get good profits from sericulture by taking advantage of favorable agreements and total low costs. This made them uninterested to invest capital in modernization of production technology;

$>$ Increasing taxation on silk production and $\operatorname{trade}^{24}$ put silk industry in not convenient development perspective and persuaded landowners to pay more attention in seeking alternatives - more lucrative crops (as olive trees and vineyards) or other textiles.

Malanima states Calabria maintained the same level of raw silk production (about 100-200 tons per year) until 1860 , with the difference that in year 1500 population was about 600.000 people and silk production amount to approximately $50 \%$ of the whole European production. Three centuries later population grew to over 900.000 and silk production reduced to $5 \%$ of the total amount of silk processed in Europe (Malanima, 2004 ).While the northern part of the region (Calabria Citeriore), for geographical and cultural reason but also because lack of infrastructure, linked trade towards Naples by limiting production on raw silk only, southern part of the region (Calabria ulteriore) experimented with selling its silk products towards international markets, through free port of Messina. Previously enabled Calabria ulteriore be ready for future industrialization process (that in 19th century made it competitive again on a European scale).

The combination of negative social and economic factors, coupled with rural crisis, resulted with failure of modernization in sericulture. Despite the production continued at the same level until the beginning of 19th century, the progressive loss of market share (caused by the decreasing quality of the silk product) benefited most dynamic competitors from other Italian, European and Asiatic regions. Abowe mentioned system of production lasted immutable two centuries (until the 19th century), with an increasing differentiation between regional specialization. The 19th century was extremely important for Calabria and Italian history in general. Many relevant events shocked the status quo and had a decisive impact over Calabrian society, economy and culture by replacing outdated structures with new ones. For example, the Napoleon conquest and rule on Naples (18061815) spreaded the ideas of the French revolution leding to the abolition of feudal privileges and to other measures of constitutionalism, as well as creating a new consciousness of political equality, freedom and popular sovereignity. The fall of The Kingdom of Naples following Garibaldi's military

\footnotetext{
${ }^{23}$ First package of regulation related to sericulture was introduced in 1580 when in Naples a new corpus of laws known as Arrendamento was promulgated in workshops and sold to the merchants).

${ }^{24}$ The Kingdom of Napoli was under Spanish crown, at that time, it means the collected money through the taxes in the main were used to finance military campaigns to expand or defend the territory of the Spanish monarchy and to conquer new colonies in America.
} 
expedition and the proclamation of The Kingdom of Italy under the Savoy dinasty (1861), led to the end of Bourbon economic protectionism. Previously mentioned brought years of brigandage, social unrests, ravages and supressions. The new nation was created followed by economic, monetary and customs policy oriented towards market liberalization and world competition.

As regards, in the second half of 19th century, sericulture in Calabria got into major crisis due of a number not solved problems from the past (lack of infrastructure, bad administration, difficulties in gaining access to credit, presence of a local leadership more interested to defend its privileges rather than opening up to the changes and challenges of new global market).

The worsened economic conditions, the disastrous earthquakes of 1904 and 1908 and the outbreak of the First World War (1915-1918) caused the closure (or their conversion into cocoon dryers) (Marcelli , 2005) of most of the spinning mills and, de facto, the end of silk production in Calabria. However the silkworm rearing and the selling of dried cocoons (2.000.000 $\mathrm{kg}$ in 1926) to North Italian industry, in steady decline lasted many years more until the end of Second World War (Marcelli, 2013). The most remarkable event was the outbreak of pebrine disease that initially spread from France (1848) to other industrial farms in Northern and Central Italy (1850). Pebrine disease produced serious damages and because of this could be seen as most responsible for the failure of sericulture in Europe. Merchants started to search in every country healthy cocoons and silkworm seeds. In this period Calabria experienced a strong expansion of raw silk export, mainly direct to France, USA and Russia, because in that time Calabria still had a healthy seeds. Global development, ndustralization and high international demand for healthy seeds and silkworm increased.

As sericulture has an international character and the silk markets were connected, this means that every crisis or significative political or economic change that happened somewhere (in Asia or America) had an impact/influence on every remote silk area all over the world. For example the opening of Suez channel in 1869 connected the Red Sea and Mediterranean Sea developed sea transport of goods and commodities. Also, this channel made easier access to the Asian silk markets and the loss of competitiveness of European silk products.

The agricultural crisis from 1875 affected South Italy strongly. This crisis was caused by the decision of the Italian Government to import wheat and other goods from Russian Empire and USA. As an attributable consequence the fall in prices of agricultural products happened, resulting the ruin of thousands of small producers and farm workers. This implied an additional decline in living standards (such as: low salaries, an increased unemployment rate etc.) which caused the mass internal and external migrations (from villages towards cities, and from marginal undeveloped areas towards the USA, South America and Northern Europe). 
The rationalization of agricultural production in the late 19th century brought new economic turn. The rising imports from Far East represented the end of Calabria sericulture as a relevant economic activity. Sericulture lasted on an industrial scale until 1918 especially in Reggio Calabria district $^{25}$. Sericulture stayed some more time after WWII as self-sustainable additional activity on small production level, until the emergence of new and cheaper substitute - synthetics.

The end of silk production in Calabria meant the end important, but also stopped economic activity. Unfortunately the loss of a thousand years old cultural heritage is inevitable, if future attempts of revializing the tradition fails. In contemporary context with new technologies in production, transport and marketing options, recovering the historical memory and knowledge of sericulture could represent the option for a higher quality and specialized sustainable economic activity.

\section{The new bright perspectives for silk revitalization in Calabria}

In our research we have selected three positive examples from Calabria region that could represent cases for blueprinting in other countries and regions with similar silk history. We recognized three initiatives that happened within Calabria municipalities: Mendicino, San Floro and Acri. These initiatives represent partnerships between the civil sector and the state, which were later recognized and supported by EU funds.

Mendicino municipality still has strong marks related to silk. Namely, on the municipality building facade, there is an integrated sculpture of silk bug cocoon - as a municipality brand and clear identity. There is a museum which is constantly open, with traditional basic sericulture equipment. In this municipality, silk production is still happening on a small scale, by several old women who preserved the tradition and knowledge of silk processing and breeding silk bugs. Sericulture lives through women's entrepreneurship at the level of Mendicino municipality.

San Floro example we found most interested and complete. This project was initiated twenty years ago, by its Major. He recognized the importance of silk revitalization and production that was historically very important in this municipality area. Initial support was done by the municipality through planting 3000 mulberry trees, which are necessary for silk bug breeding. At this initial point project was seen as a long-term, first supported by the municipality. After retirement of the mayor, new generation of young people from the municipality continued to work on the project. They organized the activities through starting the museum, workshops for the production of silk bugs and cocoons, production of scarves and silk jewelry, production of secondary products - mulberry jam, mulberry liquor, but also they organized tours and visits

\footnotetext{
${ }^{25}$ Despite the frequent destructive earthquakes (1894, 1905 and 1908) had heavily damaged spinning mills and infrastructure.
} 
to these production places for schools and tourists. Year-by-year the visits growth have increased a few hundred times. This project is most sustainable because it is depended on three young people that are highly motivated, educated and using silk narratives to talk stories around silk, with (cultural, touristic, educational and economic) sustainable components. This project represents optimal mix of knowledge from cultural, creative tourism and entrepreneurship that led to the synergy and added values.

Acri municipality is an example of cooperative where the silk production is taking place on a traditional old craft level. They started this project with an expert who had the knowledge about silk production. The mission is about re-starting silk production, workshops and courses in order to contribute and help vulnerable groups by their inclusion into processes and also other forms of social assistance.

We can conclude that restoration of silk production should stay on the small scale and it is fully possible in places with real history and silk tradition. Also, in all three mentioned cases new forms of responsible entrepreneurship and mix of creative and cultural economy with SMEs represent a key element for synergies and sustainability of silk revitalization. Moreover, as the contribution to sustainable development, we recognized responsible forms of (social, creative and cultural, women's) entrepreneurship and tourism, which in combination generate added values.

\section{BIBLIOGRAPHY}

Anania Giovanni, 2001, Scelte pubbliche, strategie private e sviluppo economico in Calabria,

Rubettino, Soveria Mannelli, p. 192.

Capalbo Cinzia 2004, La seta nella storia economica della Calabria in Seta e moda dalla filiera della seta alla produzione tessile, Rubettino Editore, Soveria Mannelli, p.23.

Chao Kang, 1984, La production textile dans la Chine traditionelle, Annales: Economic, Societes, Civilisations XXXIX, Paris pp: 957-976.

Cizakca M., 1985, Incorporation of the Middle East into European World-Economy, Review VIII New York, pp: 353-377.

Federico Giovanni 1994, Il filo d'oro, l'industria della seta dalla Restaurazione alla grande crisi, edizioni Marsilio, Padova.

Federico Giovanni 1997, An economic history of silk industry 1830-1930, Cambridge, Cambridge University Press

Federico, G., 2009, An economic history of the silk industry, 1830-1930, Cambridge Studies in Modern Economic History, Cambridge University press, digitally printed version. 
Fusco Ida Maria (editor) 2004, La seta e oltre ... Edizioni Scientifiche Italiane, Napoli.

Galasso Giuseppe 1975, Economia e societa' nella Calabria del '500, Guida Editore, Napoli, p. 143

Herzig E., 1990, The Iranian Raw silk trade and European Manufacture in the 17th centuries, Journal of European Economic History XIX Rome, pp: 73-90.

K.N.Chaudhuri, 1974, The structure of Indian Textile Industry in $17^{\text {th }}$ and $18^{\text {th }}$ centuries, The Indian Economic and Social History Review XI (1974), pp. 127-142.

Luciano Cafagna, Giovanni Federico, 1992, La Seta in Europa SEC.XIII-XX, International conference 4-9 may, ch: The World Silk Trade: A long period overview pp: 634-683.

Malanima Paolo, Le sete della Calabria in Fusco Ida Maria (editor) 2004, La seta e oltre ... p.55-68

Manuel Mino Grijalva, Proto-Industria Colonial, Historia Mexicana XXXVIII (Mexico, 1989), pp 793-818.

Marcelli Angelina 2005, Luigi Alfonso Casella e la sericoltura calabrese tra Otto e Novecento,

Rubettino Editore, Soveria Mannelli, p.155.

Marcelli Angelina 2013, Produzione serica, cultura contadina e politiche di intervento pubblico in eta' contemporanea. una storia nascosta: il caso della Calabria, Aracne, Roma, p.211.

Mattiebelle Gittinger, Master Dyers to the World: Technique and Trade in Early Indian Dyed Cotton Textiles, The textile Museum (Washington, D.C., 1982), pp.137-191. and see also Textiles and the Tai Expirience in Southeast Asia, The textile Museum, ch 3 and 4

Mazzaoui Fennell Maureen, 1997, Textiles: Production, Trade, Demand, An expanding World: The European Impact on World History 1450-1800, vol 12.

Mehmet Genc 1996, The Economy and Changes in Economic Though in the $18^{\text {th }}$ century, forthcoming in the proceedings of the International conference on The Ottoman State, Modernism and the EuroIslamic Synthesis: A revisited approach, The University of Wisconsin-Madison

Morris Rossabi 1990) The Decline of the Central Asian Caravan Trade, ed James D. Tracy, The rise of Merchant Empires: Long-distance Trade in the Early Modern World ( , Cambridge 1990), pp. 351 370.).

N.B.Harte and K.G. Pointing The rise of protection and the English Linen Trade, 1690-1790, in eds., , Textile History and Economic History, Manchester 1973, pp.75-112.

Osamu Saito, 1983 Population and the peasant Family Economy in Proto-Industrial Japan, Journal of Family History VIII no.1 pp 33-54 
P. Kriedtc, H. Mcdick and j. Schlumbohm, Industrialization before industrialization (Cambridge, I98I). Translated by B. Schempp, first published as Ihdustrialisierung vor der Industriali.sieruyng (Gdttingen, 1977). (Henceforth KMS)

Placanica Augusto 1999, Storia della Calabria: dall'antichita' ai giorni nostri, Donzelli Editore, Roma

Rab Houston and K. D. M. Snell, 1984, Proto-Industrialization? Cottage Industry, Social Change, and Industrial Revolution Author(s): Source: The Historical Journal, Vol. 27, No. 2 (Jun., 1984), pp. 473 492 Published by: Cambridge University Press Stable URL: http://www.jstor.org/stable/2639188

Ragosta Rosalba 2009, Napoli citta'della seta, Donzelli Editore, Roma, p.31

Sinnappah Arasaratnam, Merchants of Coromandel in Trade and Entrepreneurship 1650-1700, Comodities and Entrepreneurship, pp 37-51.

William B. Hauser, 1974, Economic Institutional Change in Tokugawa Japan: Osaka and the Kinai Cotton Trade. London: Cambridge University Press 